prior exposure to any of the stimulant drugs). When spontaneous secretion had returned to a low level perfusion was once more switched, this time to Locke's solution plus nicotine. Nicotine then exerted its familiar powerful excitant effect raising secretion to more than $10 \mu \mathrm{gm} . / \mathrm{min}$. Similar results were obtained with TMA, lobeline and DMPP.

It thus appears that these various drugs of the 'nicotine group' may all evoke catecholamine secretion by causing calcium ions to penetrate the medullary cells.

\section{W. W. Douglas}

R. P. RUBIN

Department of Pharmacology,

Albert Einstein College of Medicine, New York 61.

${ }^{1}$ Douglas, W. W., and Rubin, R.P., J. Physiol., 159, 24 (1961); Biochem. Pharmacol. 8, 20 (1961).

2. Douglas, W. W., and Rubin, R. P., J. Physiol. (in the press).

\section{PHARMACOLOGY}

\section{A New Potent Analgetic Antagonist}

THE discovery of a new potent analgetic with a reduced liability to addiction ${ }^{1}$ in the benzomorphan series, namely, 2'-hydroxy-5,9-dimethyl-2-phenylethyl-6,7-benzomorphan ${ }^{2}$ (I), has suggested further work in the series. 2'-Hydroxy $=5,9$-dimethyl-2-allyl6,7-benzomorphan (III) is a potent antagonist of phenazocine, morphine, meperidine, and other analgetic agents. This compound is of special interest in that combinations of phenazocine and III in ratios of $5: 1$ to $100: 1$ retain analgetic activity in onimals yet seem to be relatively devoid of physicel dependence properties in the monkey in both acute and chronic experiments (hiological details of this work will be described elsewhere).

The demethylation of $2^{\prime}$-hydroxy-2,5,9-trimethyl6.7-benzomorphan has been described ${ }^{2}$. Reaction of the nor-compound (II) with a slight excess of allyl bromide in ethanol containing sodium bicarbonate for $18 \mathrm{hr}$. under reflux gave, after filtration, concentration and trituration with ether, the product (III), m.p. $141-144^{\circ}$ in 46.5 per cent yield. Anal. calc.: $\mathrm{C}_{17} \mathrm{H}_{23} \mathrm{NO} ; \mathrm{C}, 79 \cdot 33 ; \mathrm{H}, 9.01 ; \mathrm{N}, 5.44$. Found: C, $79 \cdot 06,78 \cdot 99 ; \mathrm{H}, 9 \cdot 19,9 \cdot 29 ; \mathrm{N}, 5 \cdot 64,5 \cdot 78$.

A mixture of 5,9-dimethyl-2' -methoxy-6,7-benzomorphan (IV), prepared by treating 5,9-dimethyl2'-hydroxy-6,7-benzomorphan ${ }^{2}$ (II) in ethanol with diazomethane in ethanol containing sodium bicarbonate was treated with allyl bromide under reflux. After appropriate working up, the residue was dissolved in acetone and treated with ether to give the desired product (V), m.p. 216-218 ${ }^{\circ}$, for the hydrochloride salt. Anal. calc. for $\mathrm{C}_{18} \mathrm{H}_{25} \mathrm{NO} . \mathrm{HCl}$ : C, 70.22 ; $\mathrm{H}, 8.51 ; \mathrm{N}, 4.55$. Found: C, 70.00; H, 8.50; N, $4 \cdot 78$.

The present antagonist (III) combined with phenazocine in a $1: 1$ ratio showed no analgesia, and precipitated abstinence phenomena in the morphine- addicted monkey (Deneau, G. A., and Seevers, M. H., private communication). With a ratio of 9 parts of phenazocine to 1 of the antagonist (III), the analgesic effect was as good as with phenazocine alone, and there was a precipitation of abstinence in addicted monkeys as seen with nalorphine, instead of a suppression. Mixtures of 25:1 and 50:1 acted similarly; with a $100: 1$ mixture there was no precipitation of abstinence and no suppression up to a dose of $16 \mathrm{mgm} . / \mathrm{kgm}$. The retention of good analgesic effect without suppression of abstinence, indeed with the presence of nalorphine-like effects with respect to precipitation of abstinence in morphine-addicted animals, seems very promising and these mixtures will be studied in man. The antagonist (III) itself showed no significant analgesic effect in animals.

An analgesic effect of nalorphine in man, and retention of the analgesic effect of morphine in appropriate mixtures of morphine and this antagonist, were first reported by Beecher and Lasagna ${ }^{3}$. Later it was shown that morphine-nalorphine mixtures administered repeatedly to former addicts (Fraser, H. F., and Isbell, H., personal communication) produced a milder degree of physical dependence than equivalent doses of morphine alone. N. B. Eddy, M. Piller, L. A. Pirk, O. Schrappe and S. Wenda have shown that when mixtures of morphine and levallorphan (an antagonist of the morphinan group) were administered for chronic pain there was a definite trend toward delay in the development of tolerance and physical dependence under clinical conditions.

\section{Maxwell Gordon \\ JOBN J. LAFFERTY \\ Davin H. TEDeschi}

Smith Kline and French Laboratories, Philadelphia 1.

Nathan B. Eddy
Everette L. May

Laboratory of Chemistry,

National Institutes of Health, Bethesda 14, Maryland.

${ }^{1}$ Fraser, H. F., and Isbell, H., Addendum to Minutes of Twentieth Meeting, Committee on Drug Addiction and Narcotics, January 10-11, 1959 (Nat. Acad. Sei.-Nat. Res. Council)

2 May, E. X., and Eddy, N. B., J. Org. Chem., 24, 294 (1959).

${ }^{3}$ J. Pharmacol. Exp. Therap., 112, 356 (1954).

Bull. Narcotics, $12(4), 1$ (1960).

\section{Anti-Asthmatic Effect of Phenazone and Amidopyrine}

MANY chronic asthmatics state that they obtain relief from proprietary asthma powders available in Germany without medical prescription. Mast of these powders contain either phenazone or amidopyrine, besides much smaller quantities of various other ingredients. In the list of German proprietaries (the "Red List"), we have found 53 such preparations, of which 27 contained phenazone, 22 amidopyrine and 4 both.

As little seems to be known about the anti-asthmatic effects of phenazone and amidopyrine, we have investigated the question in $\mathbf{4 6}$ patients with chronic asthma, who were trained in spirometry. In each experiment the patient's vital capacity was recorded successively three or more times, and he was then given placebo or drug by mouth. $1 \mathrm{hr}$. later a second series of vital capacities was recorded as before. The 